\title{
Glycine Induced Hyperammonemia After Bladder Rupture During Transurethral Resection of a Bladder Tumor
}

\author{
Paul Dohrenwend ${ }^{\mathrm{a}}$, Richard D. Shih,
}

\begin{abstract}
Glycine is widely used as an irrigation fluid for transurethral procedures and rarely causes glycine toxicity. We report a case of profound hyperammonemia occurring from complications of a transurethral resection of a bladder tumor in a female. To our knowledge, no previously published report documents such a high serum ammonia level. A 76-year-old female with a past medical history included hypertension and hyperlipidemia underwent transurethral resection of the bladder tumor (TURBT). During her operative procedure the patient was found to have an invasive bladder tumor, which was resected using a resectoscope. During the procedure she received 24 liters of $1.5 \%$ glycine irrigation fluid. After the procedure the patient was found to have a distended lower abdomen. A retrograde cystogram confirmed that a rupture of the bladder occurred with extravasation of large amounts of fluid, thought to be glycine irrigation fluid. While in the recovery room the intubated patient was following simple commands. Her initial post-operative serum sodium level was $120 \mathrm{mmol} / \mathrm{L}$. The patient was treated with normal saline continuous bladder saline irrigation and CT guided percutaneous drainage of the fluid collection. Twenty hours after the procedure the patient had an episode of tonic-clonic muscular activity. She was treated successfully with phenytoin and midazolam. The sodium decreased to a low of $109 \mathrm{mmol} / \mathrm{L}$ and the ammonia level peaked at 1,592 $\mu \mathrm{mol} / \mathrm{L}$. The patient underwent hemodialysis on post-operative day one. Three days after the procedure the patient was extubated and at her baseline mental status. Her ammonia levels returned to normal by day two. She was discharged from the hospital without neurological sequelae. Severe hyperammonemia is possible after massive pelvic and intraperitoneal glycine absorption. Such toxicity is survivable and can be associated with altered mental status and seizures.
\end{abstract}

Manuscript accepted for publication January 2, 2013

${ }^{a}$ Department of Emergency Medicine, Morristown Medical Center, Morristown, NJ, USA

${ }^{\mathrm{b}}$ Corresponding author: Richard D. Shih, Department Of Emergency Medicine, Morristown Medical Center, Morristown, NJ 07962, USA. Email: shih100@yahoo.com

doi: http://dx.doi.org/10.4021/jmc1054w
Keywords: Glycine; Ammonia; Transurethral resection of the prostate syndrome; Bladder rupture; Irrigant extravasation; Glycine toxicity; Hyponatremia; Hyperammonemia

\section{Introduction}

Glycine, widely used as an irrigation fluid for transurethral procedures and endometrial procedures, has been shown to be a safe irrigant. However, adverse reactions from irrigant absorption occur with some frequency [1]. The most frequent adverse event, irrigation absorption syndrome, is characterized by hyponatremia, confusion, lethargy, coma, headache and visual disturbances [2, 3]. Hyperammonemia is a known sequelae of glycine toxicity. Glycine toxicity usually occurs from absorption of the irrigation fluid during procedures. Massive absorption of irrigation fluid through a bladder rupture is infrequent. We report a case of profound hyperammonemia occurring from complications of a transurethral resection of a bladder tumor in a female. During the procedure the bladder was ruptured with massive absorption of glycine irrigation solution and resulting severe hyperammonemia. No published documents report such high serum ammonia levels.

\section{Case Report}

A 76-year-old female was admitted to the hospital for a transurethral resection of the bladder tumor (TURBT) with a one week history of gross hematuria and pelvic pain. Three weeks prior to admission she was treated for a UTI with moxifloxacin. An abdominal CT showed a bladder mass and a right hydronephrosis consistent with invasive bladder cancer.

Her past medical history was significant for hypertension and hyperlipidemia. Her only medication was irbesartan. She had no prior surgeries. Physical examination revealed a supple neck without jugular venous distension. Her lungs were clear. Her cardiovascular exam was normal with no murmur. Her abdomen was soft, non-tender and non- 
Table 1. Serum Sodium and Ammonia Levels Post Procedure

\begin{tabular}{|c|c|c|c|}
\hline Hours post procedure & $\begin{array}{l}\text { Sodium } \\
\mathrm{mmol} / \mathrm{L}\end{array}$ & $\begin{array}{l}\text { Ammonia } \\
\mu \mathrm{mol} / \mathrm{L}\end{array}$ & $\begin{array}{l}\text { Osmolarity } \\
\mathrm{mOsm} / \mathrm{kg}\end{array}$ \\
\hline Pre-operative & 138 & - & - \\
\hline 0 & 120 & - & - \\
\hline 2 & 114 & - & - \\
\hline 2.5 & 101 & - & - \\
\hline 3.0 & 107 & - & - \\
\hline 4 & 109 & - & - \\
\hline 5 & 109 & 902 & - \\
\hline 5.5 & 111 & 1,592 & 279 \\
\hline 6 & 118 & - & - \\
\hline 7.5 & 116 & 613 & - \\
\hline 10 & 119 & 144 & 282 \\
\hline 14 & 123 & 30 & - \\
\hline 18 & 126 & 26 & 285 \\
\hline 31 & 141 & - & - \\
\hline 43 & - & 6 & - \\
\hline 63 & - & 5 & - \\
\hline
\end{tabular}

distended. Her liver and spleen were normal. There was no costovertebral tenderness. There was no urethral prolapse. There was no adenexal tenderness and no cervical motion tenderness on pelvic examination. Her pre-operative laboratory values were sodium, $138 \mathrm{mmol} / \mathrm{L}$, potassium, 4.0 $\mathrm{mmol} / \mathrm{L}$, bicarbonate, of $23 \mathrm{mmol} / \mathrm{L}$, glucose, $120 \mathrm{mg} / \mathrm{dL}$, BUN, $16 \mathrm{mmol} / \mathrm{L}$, creatinine, $1.2 \mathrm{mg} / \mathrm{dL}$. Urinalysis revealed microscopic hematuria, leukoesterase and nitrites.

During her operative procedure the patient was found to have an invasive bladder tumor, which was resected using a resectoscope under direct observation. There was no obvious bladder perforation. Indigo carmine was given to evaluate the ureteral orifices. The right ureter was never seen. The left ureter was clearly seen. All the bladder chips were removed using the Ellik evacuator and hemostasis was meticulously controlled. During the procedure she received 24 liters of $1.5 \%$ glycine irrigation fluid. After the procedure the patient was found to have a distended lower abdomen. A retrograde cystogram confirmed that a rupture of the bladder occurred with extravasation of large amounts of fluid, thought to be glycine irrigation fluid, into the peritoneal cavity.

While in the recovery room the intubated patient was following simple commands. Her initial post-operative serum sodium level was $120 \mathrm{mmol} / \mathrm{L}$. The patient was placed on intravenous normal saline at $50 \mathrm{~mL} / \mathrm{hr}$ and continuous bladder irrigation with $0.9 \%$ normal saline. One hour later her serum sodium was $114 \mathrm{mmol} / \mathrm{L}$. $200 \mathrm{ml}$ of 3\% hypertonic saline was administered over 8 hours. Intravenous gentamycin was also administered.

An abdominal CT scan revealed significant amounts of fluid in the abdomen, pelvis, and a moderate sized collection in the prevesicular space extending over the dome of the bladder. CT guided percutaneous drainage of the fluid collection with an 18 French J-Thal catheter was performed, 2.5 
L of clear fluid was collected from this catheter. Repeat CT scan showed significant decrease in the fluid collections. She was transferred to the ICU for monitoring and care. Twenty hours after the procedure the patient had an episode of tonicclonic muscular activity. She was treated successfully with phenytoin and midazolam.

The patient's serum sodium and ammonia levels are listed in Table 1. The sodium decreased to a low of $109 \mathrm{mmol} / \mathrm{L}$ and the ammonia level peaked at 1,592 $\mu \mathrm{mol} / \mathrm{L}$. The patient underwent hemodialysis on post-operative day one. Three days after the procedure the patient was extubated and at her baseline mental status. Her ammonia levels returned to normal by day two. She was discharged from the hospital without neurological sequelae.

\section{Discussion}

Transurethral surgeries have been performed since the 1930s to resect prostate tissue and bladder tissue. The procedure involves a rectoscope that contains a wire loop electrode and is inserted through the urethra. The electrocautery loop can resect tissue and coagulate bleeding via coagulation current. To visualize the tissue being resected an irrigation fluid is used that is electrically inert and provides a clear field. Initially, distilled water was utilized. However, this was associated with intravascular hemolysis and water intoxication [3]. To avoid hemolysis, solutions of mannitol, sorbitol, or glycine were used.

Use of mannitol is associated with hyponatremia. Sorbitol usage has been associated with cerebral edema [3]. Glycine has a lower risk for hyponatremia and cerebral edema and fulfills criteria for an ideal irrigating solution: it is nonelectrolytic, non-toxic, easily sterilized and inexpensive [4, 5]. Because of these characteristics, it has become the most commonly used irrigation fluid for transurethral procedures [6].

A typical transurethral procedure utilizes an average of $20 \mathrm{~L}$ of irrigation solution. Most patients are expected to absorb $1 \mathrm{~L}$ to $2 \mathrm{~L}$ of irrigant in a procedure that usually lasts approximately 40 minutes [7], when bladder rupture occurs large amounts of solution enters the peritoneal cavity. This can lead to a massive absorption, as in this case. Only one other report of bladder rupture and massive irrigation is reported [8].

When large amounts of glycine irrigation fluid are absorbed systemically a symptom complex known as Irrigation Absorption Syndrome occurs.

The onset of Irrigation Absorption Syndrome occurs minutes to hours post procedure. It occurs in about $2 \%$ of all transurethral prostate resections [9]. Factors associated with occurrence of the syndrome include duration of surgery, height of the irrigation solution, and amount of venous sinuses opened during the procedure. Altered mental status immediately after the procedure, as in our case, is a common finding in patients with irrigation absorption syndrome. Confusion, agitation, headache vomiting, muscle twitching, and seizures are commonly seen [4]. Hyponatremia and hyperammonemia are frequently reported [3, 5, 9-11].

Hyperammonemia results from glycine metablolism [3, $5,11]$. Glycine, a non-essential amino acid, is metabolized to pyruvate by glycine synthase with the liberation of ammonium ions [12]. Once formed, ammonia is converted to urea. Alternatively, a percentage of ammonia is converted to glutamine via glutamine synthase. Studies have shown both mechanisms to be highly active in glycine toxicity [5].

High levels of ammonia due to glycine absorption have been reported as high as $848 \mu \mathrm{mol} / \mathrm{L}$ [2]. Our patient's level of $1,592 \mu \mathrm{mol} / \mathrm{L}$ is the highest reported in the literature. An elevated ammonia level may cause nausea, vomiting, convulsions and altered mental status. In animal studies increased ammonia levels led to elevated brain glutamate concentrations and increased NMDA receptor activation [13]. However, animal studies do not show convincing evidence of lethality associated with increasing levels of ammonia [2, $8,14]$. Despite the extremely high levels of ammonia in our patient, the levels quickly decreased over several days without any resultant neurological sequelae.

\section{Conclusion}

Severe hyperammonemia is possible after massive pelvic and intraperitoneal glycine absorption. Such toxicity is survivable and can be associated with altered mental status and seizures. The etiology of irrigation absorption syndrome is controversial. Hyponatremia and hyperammonemia both have profound neurological effects. Further studies into the pathophysiology are needed so that any adverse effects of glycine toxicity can be managed in a directed fashion towards the metabolic abnormalities that cause glycine irrigation absorption syndrome.

\section{Grant Support}

The work was supported by Emergency Medicine Associates Research Foundation.

\section{References}

1. Osborn DE, Rao PN, Greene MJ, Barnard RJ. Fluid absorption during transurethral resection. $\mathrm{Br}$ Med $\mathrm{J}$. 1980;281(6254):1549-1550.

2. Siddiqui MA, Berns JS, Baime MJ. Glycine irrigant absorption syndrome following cystoscopy. Clin Nephrol. 1996;45(5):365-366.

3. Silver SM, Kozlowski SA, Baer JE, Rogers SJ, Sterns 
RH. Glycine-induced hyponatremia in the rat: a model of post-prostatectomy syndrome. Kidney Int. 1995;47(1):262-268.

4. Ellis RE, Carmichael JK. Hyponatremia and volume overload as a complication of transurethral resection of the prostate. J Fam Pract. 1991;33(1):89-91.

5. Ryder KW, Olson JF, Kahnoski RJ, Karn RC, Oei TO. Hyperammonemia after transurethral resection of the prostate: a report of 2 cases. J Urol. 1984;132(5):995997.

6. Inman RD, Hussain Z, Elves AW, Hallworth MJ, Jones PW, Coppinger SW. A comparison of $1.5 \%$ glycine and $2.7 \%$ sorbitol- $0.5 \%$ mannitol irrigants during transurethral prostate resection. J Urol. 2001;166(6):2216-2220.

7. Oester A, Madsen PO. Determination of absorption of irrigating fluid during transurethral resection of the prostate by means of radioisotopes. J Urol. 1969;102(6):714719.

8. Byard RW, Harrison R, Wells R, Gilbert JD. Glycine toxicity and unexpected intra-operative death. J Foren- sic Sci. 2001;46(5):1244-1246.

9. Shepard RL, Kraus SE, Babayan RK, Siroky MB. The role of ammonia toxicity in the post transurethral prostatectomy syndrome. Br J Urol. 1987;60(4):349-351.

10. Hoekstra PT, Kahnoski R, McCamish MA, Bergen W, Heetderks DR. Transurethral prostatic resection syndrome--a new perspective: encephalopathy with associated hyperammonemia. J Urol. 1983;130(4):704-707.

11. Roesch RP, Stoelting RK, Lingeman JE, Kahnoski RJ, Backes DJ, Gephardt SA. Ammonia toxicity resulting from glycine absorption during a transurethral resection of the prostate. Anesthesiology. 1983;58(6):577-579.

12. Agius: Hyponatremia after transuretheral resection of the prostate. J Royal Coll Surg Edinb 1991;36:109-112.

13. Albrecht J, Jones EA. Hepatic encephalopathy: molecular mechanisms underlying the clinical syndrome. J Neurol Sci. 1999;170(2):138-146.

14. Mizutani AR, Parker J, Katz J, Schmidt J. Visual disturbances, serum glycine levels and transurethral resection of the prostate. J Urol. 1990;144(3):697-699. 